\title{
Effect of Selective Phosphodiesterase Inhibitors on the Rat Eosinophil Chemotactic Response In Vitro
}

\author{
Alessandra C Alves, Ana Lucia A Pires, Vincent Lagente*, Renato SB Cordeiro, \\ Marco A Martins, Patricia MR e Silva/ ${ }^{+}$
}

\begin{abstract}
Departamento de Fisiologia e Farmacodinâmica, Instituto Oswaldo Cruz, Av. Brasil 4365, 21045-900 Rio de Janeiro, RJ, Brasil *Laboratoire de Pharmacodynamie, Faculté des Sciences Pharmaceutiques et Biologiques, Université de Rennes, Rennes, France
\end{abstract}

\begin{abstract}
In the present study, we have performed a comparative analysis of the effect of selective inhibitors of phosphodiesterase (PDE) type III, IV and V on eosinophil chemotaxis triggered by platelet activating factor $(P A F)$ and leukotriene $B_{4}\left(L_{3 T B}\right)$ in vitro. The effect of the analogues N6-2'-O-dibutyryladenosine 3':5' cyclic monophosphate (Bt ${ }_{2}$ cyclic AMP) and N2-2'-O-dibutyrylguanosine 3':5' cyclic monophosphate $\left(B t_{2}\right.$ cyclic $\left.G M P\right)$ has also been determined. The eosinophils were obtained from the peritoneal cavity of naive Wistar rats and purified in discontinuous Percoll gradients to $85-95 \%$ purity. We observed that pre-incubation of eosinophils with the PDE type IV inhibitor rolipram suppressed the chemotactic response triggered by $P A F$ and $L T B_{4}$, in association with an increase in the intracellular levels of cyclic AMP. In contrast, neither zaprinast (type V inhibitor) nor type III inhibitors milrinone and SK\&F 94836 affected the eosinophil migration. Only at the highest concentration tested did the analogue $\mathrm{Bt}_{2}$ cyclic AMP suppress the eosinophil chemotaxis, under conditions where Bt ${ }_{2}$ cyclic GMP was ineffective. We have concluded that inhibition of PDE IV, but not PDE III or V, was able to block the eosinophil chemotaxis in vitro, suggesting that the suppressive activity of selective PDE IV inhibitors on tissue eosinophil accumulation may, at least, be partially dependent on their ability to directly inhibit the eosinophil migration.
\end{abstract}

Key words: eosinophil - migration - phosphodiesterase inhibitors

The cyclic nucleotides are considered important second messengers in a wide variety of biological systems due to their regulatory role in the cell activity (Kaliner \& Austen 1974). The control of the intracellular levels of cyclic nucleotides has been shown to be mainly dependent on their breakdown by phosphodiesterases (PDE) (Beavo et al. 1994), which now comprises at least seven families of distinct isoenzymes (Conti et al. 1995). A variety of selective inhibitors of PDE are available, permitting the pharmacological manipulation of different physiopathological processes (Barnes 1995). Eosinophils are believed to play a relevant role in allergy and their accumulation in several tissues is considered an important feature of hypersensitivity reactions or immunologically mediated diseases (Kroegel et al. 1994). Treatment with

This study was supported by grants from Conselho Nacional de Desenvolvimento Científico e Tecnológico (CNPq) and Fundação de Amparo à Pesquisa do Estado do Rio de Janeiro (FAPERJ), Brazil.

${ }^{+}$Corresponding author. Fax:+55.21-590.9490. E.mail: patmar@gene.dbbm.fiocruz.br

Received 3 September 1997

Accepted 30 September 1997 non-selective or selective PDE IV inhibitors has been shown effective in inhibiting eosinophil recruitment after stimulation with antigen, PAF or IL-5 (Barnes \& Pauwels 1994). In this study, we have examined the ability of selective inhibitors of PDE IV as well as those of PDE III and V to inhibit the eosinophil chemotaxis in a modified Boyden chamber. The effect of the cell permeable analogues $\mathrm{Bt}_{2}$ cyclic AMP and $\mathrm{Bt}_{2}$ cyclic GMP has been also evaluated.

\section{MATERIALS AND METHODS}

Eosinophils were obtained from the peritoneal cavity of ether-anaesthetised Wistar rats and the purification was performed using Percoll density gradients ( $72 \%$ and $56 \%$ solutions). The number of cells was counted in the Neubauer chamber and the differential analysis performed in cytospin preparations stained with May-Grunwald-Giemsa dye. Cell viability was evaluated by trypan blue exclusion and eosinophils of $85-95 \%$ purity and $96 \%$ viability were used in the following experiments. For the migration experiments, 48-well microchemotaxis chamber and cellulose nitrate filters ( $3 \mu \mathrm{m}$ pore) (Neuro Probe, Inc., USA) were used in accordance with the technique described by Richards and McCullough (1984). Leukotriene 
$\mathrm{B}_{4}\left(\mathrm{LTB}_{4}\right)($ Sigma Chemical Co, St. Louis, MO) and platelet-activating factor (PAF) (Novabiochem, Switzerland) were used as chemoattractants. To test the interference of PDE inhibitors or cyclic nucleotide analogues, purified eosinophils were pre-incubated with either drug or with their respective vehicle at $37^{\circ} \mathrm{C}$ for $30 \mathrm{~min}$, in a $5 \% \mathrm{CO}_{2}: 95 \% \mathrm{O}_{2}$ atmosphere. Rolipram (a generous gift from the Institut de Recherche Jouveinal, France), SK\&F 94836 (Smith-Kline Beecham, U.K.), milrinone and zaprinast (Sigma Chemical Co, St. Louis, MO) were dissolved in $20 \%$ Tween 80 and diluted to the desired concentration with saline. $\mathrm{Bt}_{2}$ cyclic AMP and $\mathrm{Bt}_{2}$ cyclic GMP (Sigma Chemical Co, St. Louis, MO) were dissolved in saline solution. The chemotaxis chamber was incubated for $2 \mathrm{hr}$ at $37^{\circ} \mathrm{C}$ in a $5 \% \mathrm{CO}_{2}: 95 \% \mathrm{O}_{2}$ atmosphere and the filter fixed and stained as described. Eosinophils migrated at $40 \mu \mathrm{m}$ from the upper surface of the filter were counted in 15 high-power fields (hpf) and the results expressed as a coefficient migration (cf), calculated according to the formula:

$$
\mathrm{cf}=\frac{\begin{array}{c}
\text { migration in response to } \mathrm{PAF} \text { or } \mathrm{LTB}_{4} \\
\text { (with or without drugs) }
\end{array}}{\text { spontaneous migration }}-1
$$

The cyclic AMP levels were determined using a cyclic AMP $\left[{ }^{3} \mathrm{H}\right]$ assay system (Amersham International plc, UK), according to the instructions supplied by the manufacturer. Data are reported as means \pm S.E.M. and were analysed by analysis of variance (ANOVA), followed by the NewmanKeuls-Student's t test and values of 0.05 or less were considered significant.

\section{RESULTS}

Consistent with our previous observations, eosinophils presented a significant chemotactic response to PAF or $\mathrm{LTB}_{4}$, with optimal concentrations of $1 \mu \mathrm{M}$ and $0.1 \mu \mathrm{M}$ respectively (Martins et al. 1988). We noted that pre-incubation of the eosinophils with the PDE IV inhibitor rolipram (1-100 $\mu \mathrm{M})$ abrogated PAF- and $\mathrm{LTB}_{4}$-induced chemotaxis (Table I). Similarly, treatment of eosinophils with RO 20-1724, another PDE IV inhibitor, also suppressed the eosinophil migration to $\mathrm{LTB}_{4}$. Chemotaxis index of $4.8 \pm 0.7$ and $2.1 \pm 0.4$ was observed after treatment with 1 and $100 \mu \mathrm{M}$ of the RO 20-1724, respectively, when compared to that of $5.0 \pm 0.3$ for untreated eosinophils. It is important to note that no alteration of the random motility of eosinophils was noted after rolipram or RO 20-1724. Values of spontaneous migration of untreated cells were $33.1 \pm 3.5$ eosinophils/15 hpf (mean \pm S.E.M.) and the migration in the presence of $100 \mu \mathrm{M}$ of rolipram or RO $20-1724$ was $27.9 \pm$ 5.5 and $39.0 \pm 7.0$ eosinophils/15 hpf respectively.
Eosinophils treated with rolipram and Ro 20-1724 remained $>97 \%$ and $>99 \%$ viable as attested by the trypan blue exclusion. In contrast, milrinone and SK\&F 94836 (type III inhibitors) (1-100 $\mu \mathrm{M})$ and zaprinast (type $\mathrm{V}$ inhibitor) $(1-100 \mu \mathrm{M}) \mathrm{did}$ not modify the eosinophil chemotactic response to both chemoattractants (Table I). We further examined the effect of the cyclic nucleotide analogues on the chemotaxis system. Our data indicate that $\mathrm{Bt}_{2}$ cyclic AMP, though only at the highest concentration $(100 \mu \mathrm{M})$, inhibited PAF- and $\mathrm{LTB}_{4}$-induced eosinophil chemotaxis, whereas $\mathrm{Bt}_{2}$ cyclic GMP was ineffective (Fig.). To verify the relationship between intracellular cyclic AMP and inhibition of eosinophil migration, we measured the levels of this nucleotide in eosinophils. Incubation for 30 min with PDE IV inhibitor rolipram led to a 2fold increase in the intracellular levels of cyclic AMP as compared to control samples (Table II). No significant alteration in cyclic AMP levels was observed with the PDE III inhibitor SK\&F 94836 $(100 \mu \mathrm{M})$.

TABLE I

Effect of selective PDE III, IV and V inhibitors on eosinophil chemotaxis induced by PAF or $\mathrm{LTB}_{4}$ in vitro

\begin{tabular}{lrcc}
\hline Cyclic AMP & {$[\mu \mathrm{M}]$} & \multicolumn{2}{c}{ Migration coefficient } \\
\cline { 3 - 4 } modulators & & PAF & LTB $_{4}$ \\
\hline None & - & $7.07 \pm 2.07$ & $4.56 \pm 0.28$ \\
Rolipram & 1 & $1.24 \pm 1.07^{a}$ & $4.50 \pm 0.60$ \\
& 10 & $0.01 \pm 0.17^{a}$ & $2.90 \pm 0.20^{a}$ \\
& 100 & n.d. & $2.50 \pm 0.30^{a}$ \\
SK\&F 94836 & 1 & $7.71 \pm 0.99$ & $4.70 \pm 0.40$ \\
& 10 & $8.80 \pm 2.01$ & $5.10 \pm 0.30$ \\
Zaprinast & 100 & n.d. & $3.90 \pm 0.30$ \\
& 1 & $6.43 \pm 0.68$ & $4.43 \pm 0.96$ \\
& 10 & $6.73 \pm 0.86$ & $5.19 \pm 1.17$ \\
& 100 & n.d. & $3.60 \pm 0.93$ \\
\hline
\end{tabular}

Cells were pre-incubated with the tested drugs for 30 min, at $37^{\circ} \mathrm{C}$, before stimulation with PAF $(1 \mu \mathrm{M})$ or $\mathrm{LTB}_{4}(0.1 \mu \mathrm{M})$. Data represent the mean \pm SEM from a number of 3-7 experiments made in duplicate. ${ }^{a} P<0.05$ indicates statistical significance as compared to control group.

\section{DISCUSSION}

Specific and non-specific PDE inhibitors were shown to abolish allergen-induced tissue eosinophil accumulation in different animal species (Lagente et al. 1994, Elwood et al. 1995, Djukanovic et al. 1995). Our results showed that pre-incubation of eosinophils with the PDE IV inhibitor rolipram (1 to $100 \mu \mathrm{M}$ ) dose-dependently inhibited the response to PAF $\left(\mathrm{IC}_{50}=0.73 \mu \mathrm{M}\right)$, 

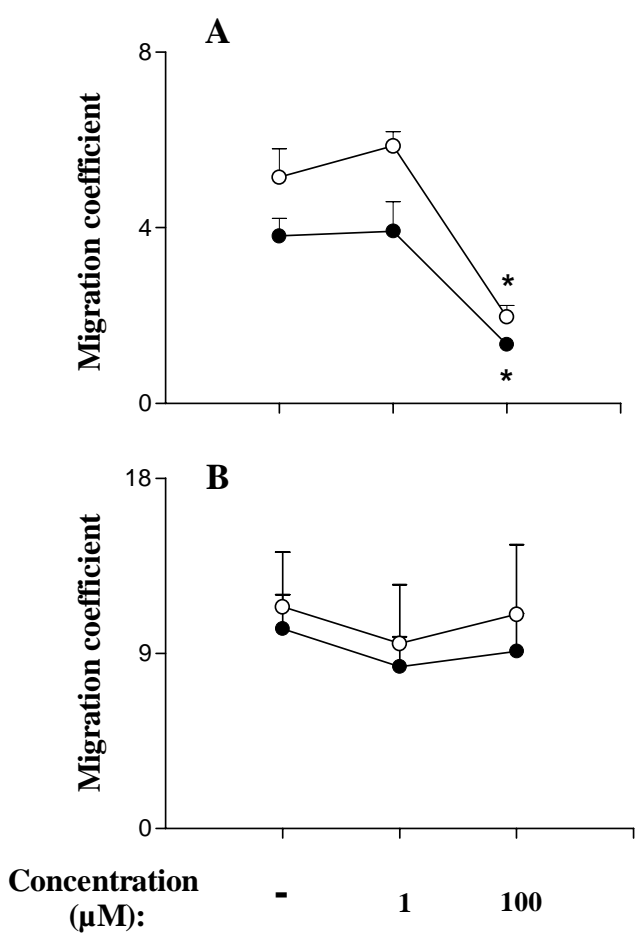

Effect of $\mathrm{Bt}_{2}$ cyclic AMP (A) and $\mathrm{Bt}_{2}$ cyclic GMP (B) on the eosinophil chemotaxis induced by PAF $(1 \mu \mathrm{M})$ (open circles) or $\operatorname{LTB}_{4}(0.1 \mu \mathrm{M})$ (closed circles). Eosinophils were treated with drugs or vehicles for $30 \mathrm{~min}$. The results are expressed as means \pm S.E.M. of 4-6 independent experiments done in duplicate. $* \mathrm{p}<0.05$ indicates statistical significance as compared to control group.

\section{TABLE II}

Effect of selective PDE inhibitors on eosinophil cyclic AMP accumulation

\begin{tabular}{lrcc}
\hline Drugs & {$[\mu \mathrm{M}]$} & $\mathrm{n}$ & $\begin{array}{c}\text { Cyclic AMP } \\
\left(\mathrm{pmol} / 2 \times 10^{6} \text { cells }\right)\end{array}$ \\
\hline None & - & 4 & $1.20 \pm 0.01$ \\
Rolipram & 10 & 3 & $2.68 \pm 0.69^{a}$ \\
SK\&F 94836 & 100 & 4 & $1.27 \pm 0.03$ \\
\hline
\end{tabular}

Cells were pre-incubated with tested drugs for $30 \mathrm{~min}$ at $37^{\circ} \mathrm{C}$. Data represent the means \pm S.E.M. from 3-4 independent experiments done in duplicate. $a: P<0.05$ indicates statistical significance as compared to control group.

while the maximal suppression of $\mathrm{LTB}_{4}$-induced eosinophil chemotaxis was approximately $60 \%$ $\left(\mathrm{IC}_{50}=48 \mu \mathrm{M}\right)$. Likewise, another PDE IV inhibitor RO 20-1724 suppressed the chemotactic response to $\mathrm{LTB}_{4}$ in the same way as rolipram. The distinct potency and efficacy with which rolipram affected eosinophil migration evoked by either PAF or $\mathrm{LTB}_{4}$ suggested that the impact of PDE IV blockade clearly depended on the type of chemoattractant receptor activated (Kita et al. 1991). Distinction in the receptor reserve and/or post-receptor signal transduction mechanisms may lead to differential sensitivity of PAF- and $\mathrm{LTB}_{4}{ }^{-}$ evoked responses to the PDE IV blockade. We also found that milrinone and SK\&F 94836 (type 111 inhibitors) and zaprinast (type $\mathrm{V}$ inhibitor) had no effect on eosinophil migration caused by both chemoattractants. At the same concentrations used in the chemotaxis assay, milrinone and SK\&F 94836 inhibited platelet aggregation triggered by ADP, whereas zaprinast enhanced the phenomenon (Alves et al. 1996). These findings confirmed that our samples of PDE III and V inhibitors were pharmacological active, and reinforced that the prominent isoenzyme in eosinophils is PDE IV (Barnette et al. 1995). In another set of experiments, we demonstrated that incubation of eosinophils with rolipram raised cyclic AMP 2.6-fold above the basal levels detected in the vehicle-treated cells. The fact that $10 \mu \mathrm{M}$ rolipram produced a modest increase in cyclic AMP levels, while abolishing the eosinophil chemotaxis, suggests the dissociation between PDE IV inhibition and changes in the intracellular levels of cyclic AMP. Nevertheless, it should be considered that the slight increase in the eosinophil cyclic AMP may be dependent on (i) the rapid/transient nature of cyclic AMP level changes, (ii) its extrusion to the extracellular environment and (iii) compartimentalization of cyclic nucleotide alterations (Vegesna \& Diamond, 1984). Alternatively, rolipram may possibly be inhibiting the eosinophil chemotactic response by mechanisms other than only PDE IV inhibition. Consistent with the lack of activity in eosinophil migration, no significant changes in cyclic AMP levels were noted with SK\&F $94836(100 \mu \mathrm{M})$. Considering the effect of the cell permeable cyclic nucleotide analogues, we observed that either PAF or $\mathrm{LTB}_{4}$ was at best inhibited to only $60 \%$ after high concentration $(100 \mu \mathrm{M})$, supporting the idea that there is not always a direct association between the suppression of biological responses and elevation of cyclic AMP levels. $\mathrm{Bt}_{2}$ cyclic GMP showed itself quite ineffective in blocking eosinophil chemotaxis.

In conclusion, our results showed that eosinophil chemotaxis can be abrogated by selective PDE IV inhibitors, but not those of PDE III or V, by a mechanism dependent on the type of chemoattractant receptor activated. In addition, they also indicated that the effectiveness of PDE IV inhibitors to abolish tissue eosinophil accumulation may be accounted for by their anti-migratory activity. 


\section{REFERENCES}

Alves AC, Pires ALA, Cruz HN, Serra MF, Diaz BL, Cordeiro RSB, Lagente V, Martins MA, Silva PMR 1996. Selective inhibition of phosphodiesterase type IV supresses the chemotactic responsiveness of rat eosinophils in vitro. Eur J Pharmacol 312: 89-96.

Barnes PJ 1995. Cyclic nucleotides and phosphodiesterases and airway function. Eur Respir J 8: 457 462.

Barnes PJ, Pauwels RA 1994. Theophylline in the management of asthma: time for reappraisal? Eur Respir J 7: 579-591.

Barnette MS, Manning CD, Cieslinski LB, Burman M, Christensen SB, Torphy TJ 1995 . The ability of phosphodiesterase IV inhibitors to supress superoxide production in guinea pig eosinophils is correlated with inhibition of phosphodiesterase IV catalytic activity. J. Pharmacol Exp Ther 273: 674-679.

Beavo JA, Conti M, Heaslip RJ 1994. Multiple cyclic nucleotide phosphodiesterase. Mol Pharmacol 46: 399-405.

Conti M, Nemoz G, Sette C, Vicini E 1995. Recent progress in understanding the hormonal regulation of phosphodiesterases. Endocrine Reviews 16: 370-389.

Djukanovic R, Howarth P, Vrugt B, Wilson S, Semper A, Bradding P, Aalbers R, Holgate S 1995. Determinants of asthma severity. Int Arch Allergy Immunol 107: 389.

Elwood W, Sun J, Barnes PJ, Giembycz MA, Chung KF 1995. Inhibition of allergen-induced lung eosino- philia by type-III and combined type III- and IVselective phosphodiesterase inhibitors in BrownNorway rats. Inflamm Res 44: 83-86.

Kaliner M, Austen KF 1974. Cyclic nucleotides and modulation of effector systems of inflammation. Biochem Pharmacol 23: 763-771.

Kita H, Abu-Ghazaleh RI, Gleich GJ, Abraham RT 1991. Regulation of Ig-induced eosinophil degranulation by adenosine 3 , ,5' -cyclic monophosphate. J Immunol 146: 2712-2718.

Kroegel C, Warner JA, Virchow JR, Matthys H 1994. Pulmonary immune cells in health and disease: the eosinophil leucocyte (part II). Eur Respir J 7: 743 760.

Lagente V, Moodley I, Perrin S, Mottin G, Junien JL 1994. Effects of isoenzyme-selective phosphodiesterase inhibitors on eosinophil infiltration in the guinea-pig lung. Eur J Pharmacol 255: 253-256.

Martins MA, Etienne A, Soulard C, Domingo MT, Braquet P 1989. Chemotactic effect of PAF-acether on peritoneal eosinophils from normal rats. Brazilian J Med Biol Res 22: 1151-1154.

Richards KL, McCullough J 1984. A modified microchamber method for chemotaxis and chemokinesis. Immunol Commun 13: 49-62.

Vegesna RVK and Diamond J 1984. Effects of isoprotenerol and forskolin on tension, cyclic AMP levels and cyclic AMP dependend protein kinase activity in bovine coronary artery. Can J Physiol Pharmacol 62: 1116-1123. 